As methods of presenting test data for use in individual diagnosis these two tables have the practical advantages that (1) they are readily understood, (2) the practical implication of the test findings is direct and unmistakeable, (3) an exact statement of the definiteness of that implication, for any case, is given.

Department of Psychology, Indiana University.

SIDNEY L. PRESSEY

- It has been outluned in a somewhat different way in a previous article. Irregularity on a Psychological Examination as a Measure of Mental Deterioration: Journal of Abnotmal Psychology. December, 1918.

\title{
THE RELATION OF SCHOLARSHIPS TO THE YERKES AND TERMAN ADULT TESTS
}

During the present collegiate year, students taking courses in Psychology and Education were tested by both the Yerkes-Rossy* adolescent-adult point scale and the Terman adult tests, by the group method. No freshmen are admitted to these classes. The results have been tabulated for the other three classes separately and for the Juniors and Seniors combined as the two latter classes take very nearly the same collegiate work. An Extension class of teachers, the majority of whom had taken 2-4 years of college work and in addition had much experience in teaching, were also given these tests. Two small classes of high school Juniors and Seniors took the Yerkes-Rossy tests. Thus there was here opportunity to compare scholastic performance with intelligence rating by two scales and also note possible diagnostic values of the different exercises.

The following tables give the mean and mean variation of each of these groups for each of the twenty exercises of the Yerkes-Rossy scale.

*Yerkes and Rossy, A Point Scale For the Measurement of Intelligence, Boston Medical and Surgical Journal CLXXVII, 564-573. 


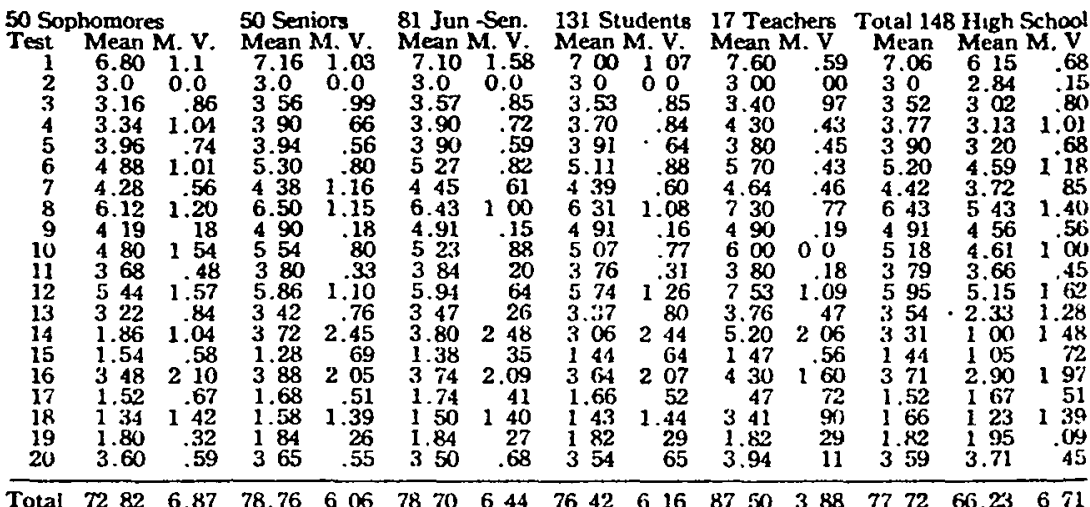

It is apparent from these results that this group of 50 college seniors obtained lower averages than those of the college women reported by Yerkes and Burtt in exercises 5, 7, 12, 13, 16, 18, and somewhat higher in exercises $1,4,8,14,17$. The averages of all these 148 college women are lower than those given by Yerkes and Burtt for tests, 5, 10,12 13,16,18, and a little higher for tests 1 , $6,7,8$, where some of the discrepancy may be due to differences in scoring. The total averages are on the whole very similar, tho somewhat higher for these seniors. It is interesting, if not significant that the 17 teachers of the Extension class exceeded the men's scores for tests 14 and 18 , as well as their general average.

Another interesting comparison with the results of Yerkes and Burtt* is in the distribution of point-scale scores, as can be seenfrom the following table which gives the percentages of each group.

\section{TABI.E II}

50

31

50

17

148

39

Siore: Simors Juniors Sophomoses Teachers Total High Sch. Jun.-

\begin{tabular}{|c|c|c|c|c|c|c|}
\hline $40-49$ & $\cdots$ & . & $20 \%$ & .. & $6 \%$ & $\begin{array}{l}\text { Sen. } \\
\quad 25 \%\end{array}$ \\
\hline $50-54$ & 1. & & $\ldots$ & . & $00 \%$ & $7.7 \%$ \\
\hline $55-59$ & . & $30 \%$ & $40 \%$ & . . & $33 \%$ & $10.2 \%$ \\
\hline $60-64$ & $40 \%$ & $3.2 \%$ & $14.0 \%$ & . & $67 \%$ & $25.1 \%$ \\
\hline 65-69 & $80 \%$ & $64 \%$ & $80 \%$ & & $67 \%$ & $7.7 \%$ \\
\hline $70-74$ & $14.0 \%$ & $161 \%$ & $220 \%$ & & $155 \%$ & $333 \%$ \\
\hline $75-79$ & $280 \%$ & $258 \%$ & $320 \%$ & $117 \%$ & $270 \%$ & $10.2 \%$ \\
\hline $80-84$ & $200 \%$ & $19.6 \%$ & $16.0 \%$ & $5.8 \%$ & $169 \%$ & $25 \%$ \\
\hline 85-89 & $200 \%$ & $161 \%$ & $00 \%$ & $41.1 \%$ & $148 \%$ & $\cdots$ \\
\hline $90-94$ & $60 \%$ & $97 \%$ & $20 \%$ & $35.3 \%$ & $88 \%$ & \\
\hline $95-100$ & . . . & . . . & $\ldots$. & $58 \%$ & $6 \%$ & \\
\hline
\end{tabular}

* Yerkes and Burtt, Relation of Point Scale Measurements to Educational Performance, School and Society, V, 535-540. 
The percentages of the upper scores are larger than those obtained for the women at Harvard, and the distribution of the entire college group of 148 women compares favorably with that obtained for their men, except at the lower end. The one student whose score fell below 50 has been asked not to return on account of poor scholarship. The conspicuous feature of the distribution of these scores is that it conforms so regularly to the expected distribution of scholarship of the different groups.

In order to estimate the diagnostic value of each of the twenty exercises the percentages of the maximum score of each one obtained by the high school students were compared with those of the college seniors and of all the college students. According to this comparison, the scores of the high school girls were equal to or slightly better than those of the college students in tests $2,11,17$, 19,20 and $7 \%$ lower in exercise 9 , and from $10 \%$ to $15 \%$ lower in tests $1,3,4,5,6,7,8,10,12,15,16,18$, while in tests 13 and 14 they were $30 \%$ and $37 \%$ lower respectively. A similar comparison between the 50 college seniors and the 50 sophomores showed that the scores of the former averaged $5 \%$ to $10 \%$ higher in exercises $4,6,10,12,13,16,17,18$, in test 14 over $26 \%$ higher, but in test $15,13 \%$ lower, and that the average scores for the other exercises were almost equal. Hence, tests $2,11,19$, and 20 seem of doubtful value for differentiating groups of the kind here examined.

With a few exceptions, due to changes in classes, the same college students took the Terman tests for years XIV, XVI, XVIII, and the teachers in the Extension class were given all the adult tests. The percentage of each of these groups that passed each of the tests is shown in the following table:

TABLE III

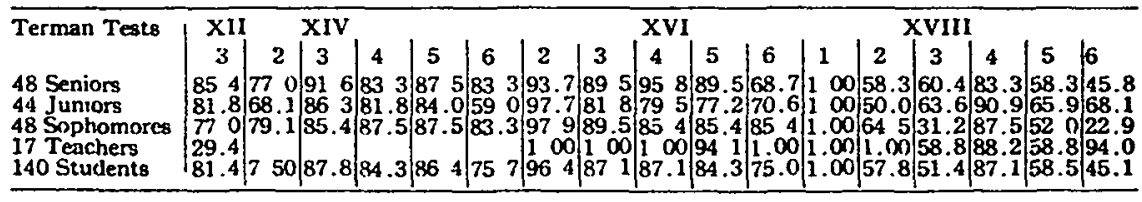

It is evident from these results, that for these teachers the BallField test was much more difficult than any of the others, and that the repetition of the digits was a much harder task than the Binet Paper-Cutting and the Ingenuity tests. The scores of the college students show that with exception of the vocabulary and Logical Memory tests, the XVIII year exercises are the most difficult, tho the clock problem is the next hardest test for the Juniors. These students found the Induction, the Code, and the Clock problems second in difficulty to the four of year XVIII. Unless a perfect score is required, the Fables are too easy as a test for these students. 
As the numerical grades of all these students are recorded, the averages of all the subjects taken by them during their college .course (in the case of the high school girls during their high school course) were used as an index of their scholarship and correlated with their Point Scale and Terman averages, giving the following coefficients $(r)$. The figures in parenthesis indicate the number of students in each class.

TABLE IV

Point Scale av. \&

Scholarship

Point Scale av. \&

Psychology av.

Suphomores Juniors-Seniors Coll. St.Teachers Jun. Sen. H.S.

Terman XIV-XVIII \&

Scholarship

$\begin{array}{llllll}.43(50) & .73(81) & .74(131) & .33 & .38 & .39\end{array}$

Terman XIV-XVIII \&

P'sychology

$\begin{array}{llll}.56 & .69 & .68 & 85(17)\end{array}$

Terman XVI-XVIII \&

Scholarship

$.21(48) \quad .38(92) \quad .30(140)$

Terman XVI-XVIII \&

Psychology

Scholarship \&

Psychology

$\begin{array}{lll}.13 & .18 \quad .16\end{array}$

Point Scale \& Terman

XIV-XVIII

Point Scale \& Terman

XVI-XVIII

$\begin{array}{lll}30 & .55 \quad .52\end{array}$

$\begin{array}{llll}.46 & .65 & .65 & .47(17)\end{array}$

$.48 \quad .41 \quad .50$

$.37(44) \quad .36(57) \quad .39(101)$

$\begin{array}{lll}.37 \quad .22 & .49\end{array}$

$.51(118)$

The most striking feature about these ccefficients is that the averages of the Terman tests give much lower correlation than the Point Scale scores. This holds true also in all my investigations with younger children. The coefficients for the high school classes are low, but the number of pupils, only 39 in all, is too small to give them much significance. It is interesting, however, to note that the coefficients increase with the higher classes, thus showing the effect of the greater maturity and the larger number of courses included in the scholarship average. It is evident that the Terman tests for the years XVI and XVIII give much higher correlation with scholarship than the combined XIV, XVI, and XVIII year exercises. In the case of psychology, the average of only the first year's courses was used, so that all the classes would be rated on the same work. Again, the Point Scale correlations are higher, tho the coefficients for the Terman Adult tests (XVI-XVIII) are nearly the same as for the Point Scale.

In conclusion, the results of these tests show that the averages of these students for the Adolescent-Adult Point Scale was higher than that obtained by Senior women at Harvard and that the dis- 
tribution of the scores resemble more closely that of the Harvard men, except at the lower end. The fact that these students were less mature and that the majority were Sophomores and Juniors will account for some of the low scores. These results also show that some of the tests are of doubtful value in differentiating the more from the less mature and able students. The correlations between mental and educational performance give higher coefficients for the Yerkes-Rossy Adolescent-Adult Point Scale than for the Terman tests for years XIV-XVIII, and also for the years XVIXVIII, tho in the latter case the difference is not so great.

Newcomb College.

DAGNY SUNNE

\section{THE GROWTH OF INTELLIGENCE}

In connection with some recent investigations on the growth of intelligence, I have been astonished by one fact which is so strikingly substantiated by several sets of data and is of such great importance, if subsequently verified, that I venture to submit it to the readers of the Journal in advance of formal presentation in a technical article.

The investigations of Terman seemed to indicate that 16 years was the upper life age limit in the growth of intelligence of average individuals. New data seem to indicate that this age should be reduced to 13 years. The facts in support of such reduction are as follows:

1. The average mental age of drafted recruits in the U.S. Army by group tests and by mental age equivalents for group test scores as indicated by clinical examinations, proved to be approximately 13 years. This may be taken to mean that mental age growth on the average was complete in these individuals at 13 years of age or thereabouts.

2. The application of the Army Alpha group test to over 500 children in a typical average grammar school of Trenton, N. J., showed increasing median scores up to the age of 13 with no increase thereafter, although a significant number of cases in the ages up to 16 years were examined. This was true for both sexes.

3 . The application of the Army Alpha group test to approximately 500 delinquent boys in the State Home for Boys at Jamesburg, N. J., showed increasing medium scores for each age group up to 13 without increasing thereafter, although a sufficient number of cases was available up to 16 years.

4. The study of continuous mental age examinations of feebleminded from the Training School at Vineland, covering at least four successive annual examinations, indicates that mental age continues to develop in all grades of feeble-mindedness up to the life age limit of 13 years. Out of 250 cases to be studied only 30 